\title{
Excessive Exercise Habits in Marathoners as Novel Indicators of Masked Hypertension
}

\author{
Young-Joo Kim, ${ }^{1}$ Yongbum Park, ${ }^{1}$ Duk-Ho Kang, ${ }^{2}$ and Chul-Hyun Kim ${ }^{2}$ \\ ${ }^{1}$ Department of Rehabilitation Medicine, College of Medicine, Sanggye-Paik Hospital, Inje University, Seoul, Republic of Korea \\ ${ }^{2}$ Department of Sports Medicine, Soonchunhyang University, Chungnam, Republic of Korea \\ Correspondence should be addressed to Chul-Hyun Kim; kimch37@sch.ac.kr
}

Received 10 October 2016; Accepted 18 January 2017; Published 15 February 2017

Academic Editor: Jason Ng

Copyright (c) 2017 Young-Joo Kim et al. This is an open access article distributed under the Creative Commons Attribution License, which permits unrestricted use, distribution, and reproduction in any medium, provided the original work is properly cited.

\begin{abstract}
Background. Excessive exercise such as marathon running increases the risk of cardiovascular events that may be related to myocardial infarction and sudden death. We aimed to investigate that the exercise characteristics can be used as a novel indicator of masked hypertension. Methods. A total of 571 middle-aged recreational male marathoners were assigned to a high blood pressure group (HBPG; $n=214$ ) or a normal blood pressure group (NBPG; $n=357$ ). A graded exercise test was used to examine the hemodynamic response and cardiac events, and the personal exercise characteristics were recorded. Results. Systolic blood pressure and diastolic blood pressure were higher in the HBPG than in the NBPG ( $p<0.05$, all). The marathon history, exercise intensity, and time were longer and higher, whereas the marathon completion duration was shorter in the HBPG than in NBPG $(p<0.05$, all). HBPG showed a higher frequency of alcohol consumption than NBPG $(p<0.05)$. Conclusion. More excessive exercise characteristics than the normative individuals. If the individuals exhibit high blood pressure during rest as well as exercise, the exercise characteristics could be used as a novel indicator for masked hypertension.
\end{abstract}

\section{Background}

Regular exercise is effective for the prevention and treatment of chronic diseases such as coronary artery disease (CAD), diabetes, obesity, hypertension, cardiac failure, and depression and reportedly extends the average lifespan of active individuals by approximately 7 years, as compared to individuals with a sedentary lifestyle [1-3]. In contrast, excessive exercise that is commonly accumulating workloads of 200 to 300 metabolic equivalent hours (METs $\times$ Hours) such as marathon [4] increases the risk of cardiovascular events that may be related to myocardial infarction and sudden death $[5,6]$. In athletes aged $\leq 35$ year, the leading cause of sudden death is hypertrophic cardiomyopathy, whereas, among athletes aged $>35$ years, the leading cause of sudden death is CAD (70\%) [7]. The risk of CAD is known to increase during middle-aged, and the primary factors involved include diabetes, hyperlipidemia, smoking, and hypertension [8]. Of these factors, hypertension exhibits the highest prevalence and is observed in nearly 1 of 3 adults
(32\%) [9]. With regard to the positive effects of exercise on hypertension, systolic and diastolic blood pressure (SBP/DBP) have been found to decrease by $4 / 4 \mathrm{mmHg}$ in a healthy group and by $11 / 6 \mathrm{mmHg}$ in a hypertension group [10]. Nevertheless, recent studies have also indicated that excessive exercises such as marathon running actually increase arterial stiffness and can promote the progression of atherosclerosis [11-13]. Moreover, the prevalence of atrial fibrillation and other arrhythmias requiring treatment is known to be higher among individuals who participate in extreme exercise than among typical individuals $[14,15]$. In particular, most participants involved in excessive exercise, such as those participating in Ironman competitions, marathons, and $100 \mathrm{~km}$ ultramarathons, are middle-aged individuals aged $\geq 40$ years [16-18]. Among these individuals, the increase in arterial stiffness and arrhythmia caused by excessive exercise is considered to be associated with hypertension [11-15]. In the present study, we aimed to assess whether the exercise characteristics in amateur, middle-aged male marathoners with high blood pressure can serve as a novel indicator of 


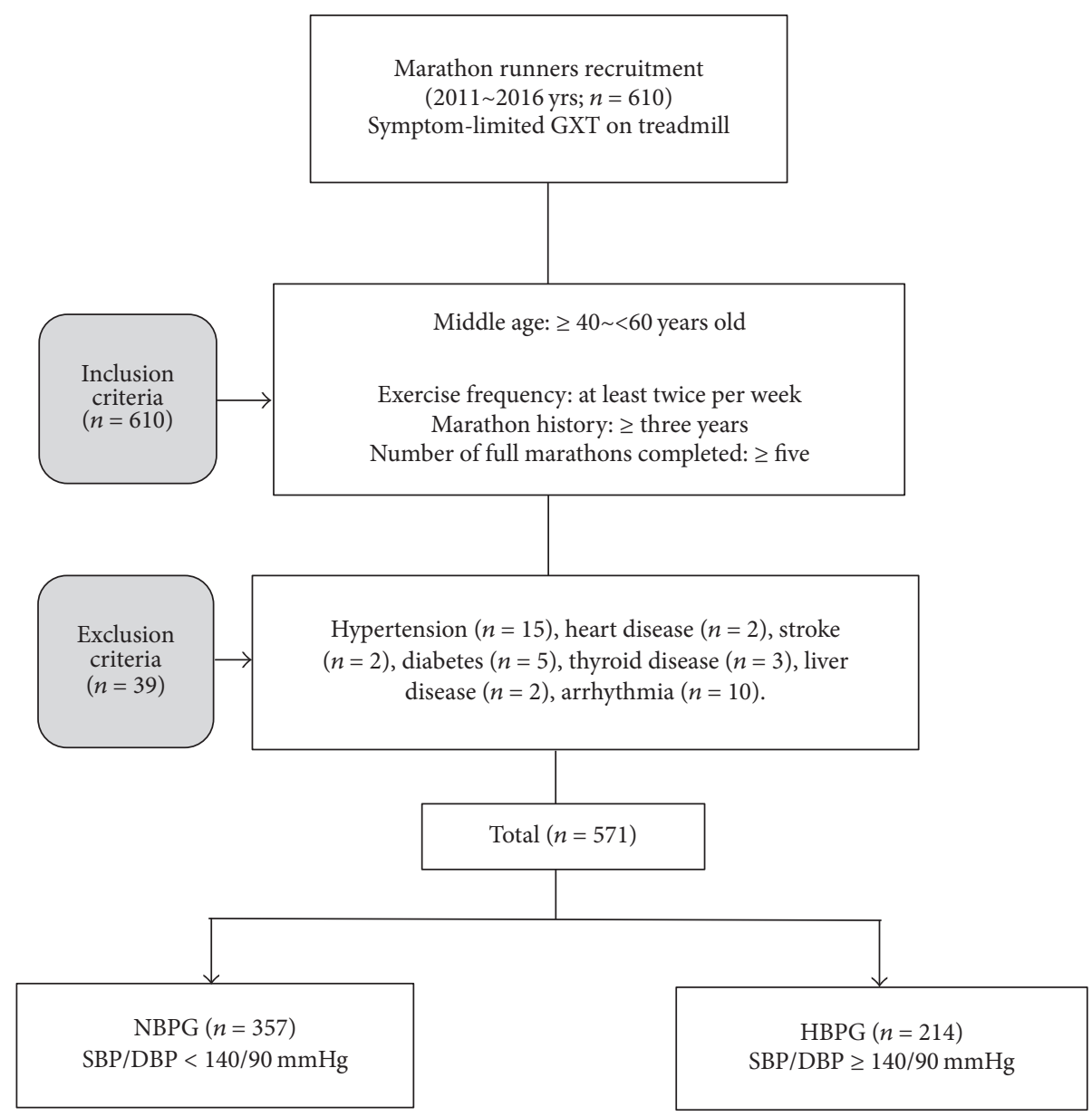

FIGURE 1: Flow chart of the study procedure. GXT, graded exercise test; NBPG, normal blood pressure group; HBPG, high blood pressure group; SBP, systolic blood pressure; DBP, diastolic blood pressure.

masked hypertension. It is hypothesized that the middleaged male marathoners with high blood pressure will show excessive exercise habits.

\section{Methods}

This is a retrospective case-control study. After receiving approval from the local ethics committee and obtaining patients' written informed consent, data from 610 middleaged male marathoners ( $\geq 40$ and $<60$ years old) who participated in a graded exercise test (GXT) for a comprehensive physical check-up at our institution between January 2011 and January 2016 were obtained via a manual review of the electronic medical records from our institution's electronic health records. All subject underwent a standardized history, physical examination.

Inclusion criteria included the following: (1) trained at least twice per week for at least 3 consecutive years; (2) completed at least 5 full marathons $(42.195 \mathrm{~km})$. Exclusion criteria included the following: (1) taking medication for hypertension $(n=15)$; (2) heart disease $(n=2)$; (3) stroke $(n=2)$; (4) diabetes $(n=5)$; (5) thyroid disease $(n=3)$; (6) liver disease $(n=2)$; (7) arrhythmia $(n=10)$. Among
610 subjects, only 571 subjects met the inclusion and exclusion criteria (Figure 1).

The resting blood pressure (RBP) of all the subjects was recorded at 5-minute intervals during a 10-minute rest period prior to GXT, and the lowest value was used for analysis. The 571 subjects were then assigned to a normal blood pressure group (NBPG; $n=214$ ), with a resting SBP/DBP of $<140 / 90 \mathrm{mmHg}$, or a high blood pressure group (HBPG; $n=357$ ), with a resting SBP/DBP of $\geq 140 / 90 \mathrm{mmHg}$. Both groups showed similar values for age, height, weight, body mass index (BMI), and smoking status, whereas alcohol consumption was significantly higher in the HBPG than in the NBPG $(p<0.01)$ (Table 1$)$.

GXT was performed on a treadmill (Medtrack ST 55, Quinton Instrument Co., USA) by using the Bruce protocol. The heart rate and electrocardiogram (ECG) data were recorded using a 12-channel Quinton stress test system (Quinton Q-4500; Quinton Instrument Co., Boston, USA) during the test. The respiratory exchange rates (RER) and maximal oxygen consumption $\left(\mathrm{VO}_{2 \max }\right)$ measurements were obtained every 15 seconds by using a respiratory gas analyzer (QMC, Quinton Instrument Co., USA). The $\mathrm{VO}_{2 \max }$ was defined as the highest value or the plateau of directly 
TABLE 1: Subject characteristics.

\begin{tabular}{|c|c|c|c|c|}
\hline Factor & $\begin{array}{c}\text { NBPG } \\
(n=357)\end{array}$ & $\begin{array}{c}\text { HBPG } \\
(n=214)\end{array}$ & $\begin{array}{c}\text { Total } \\
(n=571)\end{array}$ & $p$ value \\
\hline Age (years) & $49.1 \pm 7.7$ & $48.8 \pm 6.6$ & $49.0 \pm 7.3$ & 0.676 \\
\hline Height $(\mathrm{cm})$ & $169.9 \pm 5.3$ & $169.7 \pm 5.6$ & $169.8 \pm 5.4$ & 0.602 \\
\hline Weight $(\mathrm{kg})$ & $67.9 \pm 6.8$ & $67.3 \pm 7.9$ & $67.7 \pm 7.2$ & 0.333 \\
\hline BMI $\left(\mathrm{kg} / \mathrm{m}^{2}\right)$ & $23.5 \pm 1.9$ & $23.3 \pm 2.2$ & $23.4 \pm 2.0$ & 0.382 \\
\hline Smoking status (\%) & $10.5 \%(34)$ & $8 \%(16)$ & $8.7 \%(50)$ & 0.397 \\
\hline Alcohol (days/week) & $1.3 \pm 1.4$ & $1.8 \pm 1.9^{* *}$ & $1.5 \pm 1.6$ & 0.002 \\
\hline
\end{tabular}

The values are presented as mean \pm standard deviation or percentage (number). NBPG, normal blood pressure group; HBPG, high blood pressure group; SBP, systolic blood pressure; DBP, diastolic blood pressure; BMI, body mass index, ${ }^{* *}$ significantly different from individuals with normal blood pressure at $p<$ 0.01 .

measured $\mathrm{VO}_{2}$. $\mathrm{RBP}$ measurements were obtained while the subjects sat on a chair in the resting state for 5 minutes, and 2 values were measured with a 5-minute interval; the lowest value was used for analysis. The BP during exercise was recorded during the last minute of each 3-min stage and at the moment of maximum effort, with the arm relaxed at the side (without holding onto the side bar of the treadmill), by using an automatic BP monitor designed for exercise testing (Model 412, Quinton Instrument Co., Boston, USA). To ensure the accuracy of the measurements, the BP values were also obtained manually by placing the stethoscope microphone under the arm cuff and recording the Korotkoff sounds via a head-set. The lowest values were used for analyses. The BP and rate of perceived exertion (RPE) were initially measured 2 minutes after each stage, as well as at 1 minute after the RER of 1 was achieved in each stage. The Borg RPE scale, with values from 6 to 20, was used. The heart rate, ECG data, $\mathrm{BP}$ values, and $\mathrm{VO}_{2 \max }$ were recorded during rest and all stages. The recovery period included light walking for 5 minutes at $1.2 \mathrm{mph}$, according to the Bruce protocol. During this time, the ECG and BP data were assessed at 1minute intervals, after which all the tests were completed. Pulse pressure (PP) was recorded as the difference between the SBP and DBP. With regard to ST segment depression, upslope depression was defined as a depression of $>2 \mathrm{~mm}$, horizontal depression was defined as a depression of $>1.4 \mathrm{~m}$, and downslope depression was defined as a depression of $>1 \mathrm{~mm}$. When ST depression was observed in at least 2 leads, it was considered to indicate significant myocardial ischemia [19]. The test was discontinued if any subjective symptoms were noted, including chest pain or dizziness, or if any serious cardiac events or abnormal BP responses were observed, based on the guidelines of the American College of Cardiology/American Heart Association [19].

Information on the participating marathoners, such as marathon history (month), marathon completed (number of times), marathon completion durations ( $\mathrm{min}$ ), exercise intensity (Borg's scale), exercise duration ( $\mathrm{min} /$ day), and exercise frequency (times/week), was obtained through a questionnaire. The subjects were asked to provide the most recent record for the marathon completion duration.

2.1. Statistical Analysis. For all the data recorded in the present study, the descriptive statistics (mean, standard deviation) were calculated using the Windows SPSS/PC 17.0 statistics program, whereas between-group differences were tested using an independent $t$-test. Prior to testing the between-group differences, Levene's test was performed to confirm the homogeneity of the variance. With regard to smoking status, ST segment depression, and arrhythmia, the between-group differences in the frequency of these conditions were analyzed using a $\chi^{2}$ test. The significance level for all statistics was $p<0.05$.

\section{Results}

The hemodynamic response and cardiorespiratory fitness of all the enrolled subjects are shown in Table 2. The 2 groups showed no difference in HRrest. However, the SBPrest was found to be significantly higher in the HBPG (150.0 \pm $10.0 \mathrm{mmHg})$ than in the NBPG $(125.0 \pm 9.6 \mathrm{mmHg} ; p<$ $0.001)$, whereas the DBPrest was also significantly higher in the HBPG $(93.6 \pm 10.1 \mathrm{mmHg})$ than in the NBPG $(80.0 \pm$ $7.1 \mathrm{mmHg} ; p<0.001)$. Similarly, the HRmax showed no significant difference between the 2 groups. However, the SBPmax was significantly higher in the HBPG (227.9 \pm $23.6 \mathrm{mmHg})$ than in the NBPG $(205.6 \pm 26.1 \mathrm{mmHg} ; p<$ 0.001), whereas the DBPmax was also significantly higher in the HBPG $(77.8 \pm 15.1 \mathrm{mmHg})$ than in the NBPG $(71.5 \pm$ $11.5 \mathrm{mmHg} ; p<0.001)$. In addition, the $\mathrm{VO}_{2 \max }$ was significantly higher in the HBPG $(50.1 \pm 6.9)$ than in the NBPG $(48.6 \pm 6.7 ; p<0.05)$, and the metabolic equivalent (MET) was also significantly higher in the HBPG (794.9 \pm 101.3) than in the NBPG $(776.7 \pm 103.4 ; p<0.05)$. The Re-HR at 1 minute and Re-HR at 2 minutes did not exhibit any significant differences between the groups. However, the PPrest was significantly higher in the HBPG $(56.1 \pm 11.6)$ than in the NBPG $(44.9 \pm 8.0 ; p<0.001)$, and the PPmax was also significantly higher in the HBPG $(150.3 \pm 24.7)$ than in the NBPG $(134.1 \pm 27.8 ; p<0.001)$. Furthermore, no differences in the frequency of ST segment depression and arrhythmia were observed between the groups (Table 2).

The exercise characteristics of the 2 groups are shown in Table 3. The marathon history was significantly longer in the NBPG $(96.4 \pm 60.9)$ than in the HBPG $(80.7 \pm 44.7$; $p<0.01)$, but the number of marathons completed did not significantly differ between the groups. The marathon completion duration was significantly shorter in the HBPG 
TABLE 2: Hemodynamic response and cardiorespiratory fitness of the subject.

\begin{tabular}{|c|c|c|c|c|}
\hline Factor & $\begin{array}{c}\text { NBPG } \\
(n=357)\end{array}$ & $\begin{array}{c}\text { HBPG } \\
(n=214)\end{array}$ & $\begin{array}{c}\text { Total } \\
(n=571)\end{array}$ & $p$ value \\
\hline $\mathrm{HR}_{\text {rest }}$ (beats/min) & $65.2 \pm 10.6$ & $64.6 \pm 9.7$ & $65.0 \pm 10.3$ & 0.502 \\
\hline $\mathrm{SBP}_{\text {rest }}(\mathrm{mmHg})$ & $125.0 \pm 9.6$ & $150.0 \pm 10.0^{* * *}$ & $134.2 \pm 15.5$ & 0.000 \\
\hline $\mathrm{DBP}_{\text {rest }}(\mathrm{mmHg})$ & $80.0 \pm 7.1$ & $93.6 \pm 10.1^{* * *}$ & $85.1 \pm 10.6$ & 0.000 \\
\hline $\mathrm{HR}_{\max }$ (beats/min) & $172.9 \pm 13.1$ & $172.2 \pm 12.7$ & $172.6 \pm 12.9$ & 0.550 \\
\hline $\mathrm{SBP}_{\max }(\mathrm{mmHg})$ & $205.6 \pm 26.1$ & $227.9 \pm 23.6^{* * *}$ & $214.0 \pm 27.4$ & 0.000 \\
\hline $\mathrm{DBP}_{\max }(\mathrm{mmHg})$ & $71.5 \pm 11.5$ & $77.8 \pm 15.1^{* * *}$ & $73.8 \pm 13.3$ & 0.000 \\
\hline $\mathrm{VO}_{2 \max }(\mathrm{mL} / \mathrm{kg} / \mathrm{min})$ & $48.6 \pm 6.7$ & $50.1 \pm 6.9^{*}$ & $49.1 \pm 6.8$ & 0.013 \\
\hline MTE (sec) & $776.7 \pm 103.4$ & $794.9 \pm 101.3^{*}$ & $783.5 \pm 102.9$ & 0.040 \\
\hline Re-HR 1 min (beats/min) & $144.8 \pm 16.7$ & $145.8 \pm 16.1$ & $45.2 \pm 16.4$ & 0.484 \\
\hline Re-HR 2 min (beats/min) & $120.0 \pm 15.7$ & $120.3 \pm 15.5$ & $120.1 \pm 15.6$ & 0.815 \\
\hline $\mathrm{PP}_{\text {rest }}(\mathrm{mmHg})$ & $44.9 \pm 8.0$ & $56.1 \pm 11.6^{* * *}$ & $49.1 \pm 6.8$ & 0.000 \\
\hline $\mathrm{PP}_{\max }(\mathrm{mmHg})$ & $134.1 \pm 27.8$ & $150.3 \pm 24.7^{* * *}$ & $140.2 \pm 27.8$ & 0.000 \\
\hline ST segment depression $(\mathrm{mm})$ & $10(2.8 \%)$ & $4(1.9 \%)$ & $14(2.6 \%)$ & 0.486 \\
\hline Arrhythmia & $11(3.0 \%)$ & $3(1.4 \%)$ & $14(2.6 \%)$ & 0.209 \\
\hline
\end{tabular}

Mean \pm SD, NBPG; normal blood pressure group, HBPG; high blood pressure group, HR; heart rate, SBP; systolic blood pressure, DBP; diastolic blood pressure, MTE; maximum time to exhaustion during graded exercise test, Re: recovery time, PP; pulse pressure, ${ }^{*}$ significantly different from NBPG at $p<0.05$, **** significantly different from NBPG at $p<0.001$.

TABLE 3: Exercise characteristics of the subjects.

\begin{tabular}{|c|c|c|c|c|}
\hline Factor & $\begin{array}{c}\text { NBPG } \\
(n=357)\end{array}$ & $\begin{array}{c}\text { HBPG } \\
(n=214)\end{array}$ & $\begin{array}{c}\text { Total } \\
(n=571)\end{array}$ & $p$ value \\
\hline Marathon history (month) & $96.4 \pm 60.9$ & $80.7 \pm 44.7^{* *}$ & $90.6 \pm 55.8$ & 0.001 \\
\hline Marathons completed (number of times) & $44.4 \pm 45.3$ & $43.4 \pm 37.8$ & $44.0 \pm 42.6$ & 0.805 \\
\hline Marathon completion durations (min) & $217.4 \pm 29.6$ & $211.2 \pm 28.1^{*}$ & $214.6 \pm 29.2$ & 0.031 \\
\hline Exercise intensity (Borg's RPE scale) & $12.9 \pm 1.5$ & $13.3 \pm 1.6^{* *}$ & $13.0 \pm 1.6$ & 0.007 \\
\hline Exercise duration (min/day) & $93.7 \pm 37.0$ & $101.3 \pm 38.9^{*}$ & $96.6 \pm 37.9$ & 0.021 \\
\hline Exercise frequency (times/week) & $3.8 \pm 1.3$ & $3.8 \pm 1.4$ & $3.8 \pm 1.3$ & 0.683 \\
\hline
\end{tabular}

The values are presented as mean \pm standard deviation or percentage (number). NBPG, normal blood pressure group; HBPG, high blood pressure group; RPE, rate of perceived exertion; ${ }^{*}$ significantly different from NBPG at $p<0.05,{ }^{* *}$ significantly different from NBPG at $p<0.01$.

$(211.2 \pm 28.1)$ than in the NBPG $(217.4 \pm 29.6 ; p<0.05)$, whereas the exercise intensity was significantly higher in the HBPG $(13.3 \pm 1.6)$ than in the NBPG $(12.9 \pm 1.5$; $p<0.01)$. The exercise duration was significantly longer in the HBPG $(101.3 \pm 38.9)$ than in the NBPG $(93.7 \pm 37.0 ; p<0.05)$, but the exercise frequency did not significantly differ between the groups (Table 3 ).

\section{Discussion}

In the present study, we aimed to assess the exercise characteristics and cardiovascular factors of middle-aged male marathoners with masked hypertension. Among the 571 middle-aged male marathoners enrolled, 214 subjects were found to have high BP (mean resting SBP/DBP, $150.0 \pm$ $10.0 / 93.6 \pm 10.1 \mathrm{mmHg}$ ) and an SBPmax of $\geq 210 \mathrm{mmHg}$ (mean, $227.9 \pm 23.6 \mathrm{mmHg}$ ), which indicated the presence of exercise-induced hypertension (EIH) [20]. EIH is an independent risk factor for cardiocerebrovascular disease and is reported to increase the risk of developing hypertension later in life [21-23]. EIH increases the afterload during exercise, as a result of impaired peripheral vasodilation, thus causing an increase in the BP [24]. These mechanisms can lead to increases in BP to values greater than those in healthy individuals, even during daily exercise, and can accordingly lead to resting hypertension [23].

Moreover, the PP was significantly higher in the HBPG than in the NBPG, both at rest and after maximal exercise. As higher PP is an independent risk factor for stroke, such values could also have a negative effect on cardiocerebrovascular disease [25]. Moreover, in the HBPG, the $\mathrm{VO}_{2 \max }$ and MTE were found to be significantly higher than those in the NBPG. The MET value is obtained by dividing the $\mathrm{VO}_{2 \max }$ by $3.5 \mathrm{~mL} / \mathrm{kg} / \mathrm{min}$. In fact, Dorn et al. reported that an increase of 1MET through exercise in patients with myocardial infarction reduced the mortality rate by $10 \%$, [26] whereas Myers et al. [27] reported that an increase of 1MET corresponded to a $12 \%$ increase in survival. The higher $\mathrm{VO}_{2 \max }$ values in the HBPG than in the NBPG may be explained by their exercise characteristics. Although the NBPG showed a significantly longer marathon history than the HBPG, the HBPG exhibited shorter marathon completion durations, higher exercise intensity, and longer exercise durations, as compared to the NBPG. These findings suggest that excessive 
exercise intensity and duration can increase the $\mathrm{BP}$ at rest and during exercise, irrespective of the marathon history.

Appropriate exercise habits improve the vascular endothelial function and may have a positive impact on BP $[28,29]$, but excessive exercise such as marathon running can increase the cardiovascular risk [11, 30]. In a study by Vlachopoulos et al., marathoners who participated in chronic excessive running showed higher arterial stiffness (which could rapidly progress to atherosclerosis) than typical individuals who did not exercise [13]. An increase in the arterial stiffness was even reported after a short-term training camp for endurance runners [31]. The potential mechanisms through which excessive exercise causes increases in aortic stiffness are as follows. First, chronic pressure on the aortic wall due to extreme exercise would cause mechanical fatigue of the elastic elements of the aortic wall, thus leading to the rapid progression of fibrosis [32]. Second, repetitive episodes of high-intensity strength or endurance exercise may contribute to an increase in $\mathrm{BP}$, potentially via an increase in sympathetic activity $[33,34]$.

In general, marathoners participate in 90-300 minutes of intense aerobic exercise daily and accumulate 200-300 MET-hours per week, which is $5-10$ times higher than the recommended amount in the guidelines to prevent CAD [1]. Moreover, frequent alcohol consumption is known to be a cause of hypertension, and hence, excessive exercise characteristics and frequent alcohol consumption appear to have a combined effect on not only masked hypertension at rest, but also EIH [35].

This study has several limitations. First, the precise diagnosis of hypertension requires $24 \mathrm{~h}$ BP measurements, examinations of arterial stiffness, chest radiography, and cardiac ultrasonography. However, such examinations could not be ensured due to the large sample size. Second, psychological tension and white coat hypertension during GXT may have had an effect on the BP measurements; however, this could not be represented in the analysis. Third, although the approximate amount of alcohol consumption in the runners could be determined, it was not possible to measure the precise amount of alcohol consumption; hence, the volume of alcohol consumed could not be compared between the groups.

According to this study, it is implicated that excessive intense exercise and frequent alcohol consumption in middle-aged recreational marathoners can riskily increase blood pressure during exercise and rest and, therefore, it should be important to prescribe properly the intensity of running and to reduce the frequency of alcohol for individual marathoner's health.

Therefore, it is recommended that middle-aged marathoners should perform the annual diagnosis of graded exercise test for their healthcare.

\section{Conclusion}

Individuals with high BP had a shorter exercise history than those with normal BP. Nevertheless, the individuals with high BP still showed more frequent alcohol consumption, higher EIH, higher exercise intensity, longer exercise duration, higher $\mathrm{VO}_{2 \max }$, and shorter marathon completion durations. Thus, frequent alcohol consumption and excessive exercise are associated with high BP, not only at rest, but also during exercise, and may serve as a new indicator of masked hypertension.
Abbreviations
HBPG: High blood pressure group
NBPG: Normal blood pressure group
CAD: Coronary artery disease
SBP: $\quad$ Systolic blood pressure
DBP: Diastolic blood pressure
BP: Blood pressure
GXT: Graded exercise test
RBP: Resting blood pressure
BMI: Body mass index (BMI)
RER: Respiratory exchange rates
$\mathrm{VO}_{2 \max }$ : Maximal oxygen consumption
RPE: $\quad$ Perceived exertion
PP: $\quad$ Pulse pressure (PP)
EIH: Exercise-induced hypertension.

\section{Additional Points}

Availability of Data and Materials. Raw data supporting the obtained results are available at the corresponding author.

\section{Ethical Approval}

The ethics committee of the Inje University Medical Faculty approved the study (SGPAIK 2015-05-012).

\section{Competing Interests}

The authors declare that they have no competing interests.

\section{Authors' Contributions}

All authors read and approved the final manuscript. YoungJoo Kim and Yongbum Park designed, drafted, and wrote the manuscript, performed the statistical analysis, and collected the data. Chul-Hyun Kim has made substantial contributions to conception and design, performed echocardiography, and collected the data. Young-Joo Kim and Yongbum Park contributed equally to this works as first authors.

\section{Acknowledgments}

This work was supported by the Soonchunhyang University Research Fund (no. 20130791). They are very thankful for collaborators, Mr. Dong-Keun Shin, Mrs. Eunhee Kim, and Professor Hyeoijin Kim, for kind technical support.

\section{References}

[1] W. L. Haskell, I.-M. Lee, R. R. Pate et al., "Physical activity and public health: updated recommendation for adults from the 
American College of Sports Medicine and the American Heart Association," Circulation, vol. 116, no. 9, pp. 1081-1093, 2007.

[2] S. Sarna, T. Sahi, M. Koskenvuo, and J. Kaprio, "Increased life expectancy of world class male athletes," Medicine \& Science in Sports \& Exercise, vol. 25, no. 2, pp. 237-244, 1993.

[3] E. F. Chakravarty, H. B. Hubert, V. B. Lingala, and J. F. Fries, "Reduced disability and mortality among aging runners: a 21year longitudinal study," Archives of Internal Medicine, vol. 168, no. 15, pp. 1638-1646, 2008.

[4] H. R. Patil, J. H. O’Keefe, C. J. Lavie, A. Magalski, R. A. Vogel, and P. A. McCullough, "Cardiovascular damage resulting from chronic excessive endurance exercise," Missouri Medicine, vol. 109, no. 4, pp. 312-321, 2012.

[5] A. P. Burke, A. Farb, G. T. Malcom, Y.-H. Liang, J. E. Smialek, and R. Virmani, "Plaque rupture and sudden death related to exertion in men with coronary artery disease," JAMA, vol. 281, no. 10, pp. 921-926, 1999.

[6] N. B. Ratliff, K. M. Harris, S. A. Smith, M. Tankh-Johnson, C. C. Gornick, and B. J. Maron, "Cardiac arrest in a young marathon runner," Lancet, vol. 360, no. 9332, article 542, 2002.

[7] B. J. Maron, "Sudden death in young athletes," New England Journal of Medicine, vol. 349, no. 11, pp. 1064-1075, 2003.

[8] H. M. Mamudu, T. Paul, S. P. Veeranki, L. Wang, H. B. Panchal, and M. Budoff, "Subclinical atherosclerosis and relationship with risk factors of coronary artery disease in a rural population," The American Journal of the Medical Sciences, vol. 350, no. 4, pp. 257-262, 2015.

[9] K. M. Choi, H. S. Park, J. H. Han et al., "Prevalence of prehypertension and hypertension in a Korean population: Korean National Health and Nutrition Survey 2001," Journal of Hypertension, vol. 24, no. 8, pp. 1515-1521, 2006.

[10] R. H. Fagard and C. M. Tipton, "Physical activity, fitness, and hypertension," in Physical Activity, Fitness, and Health, C. Bouchard, R. J. Shephard, and T. Stephens, Eds., pp. 633-655, Human Kinetics, Champaign, Ill, USA, 1994.

[11] S. Möhlenkamp, N. Lehmann, F. Breuckmann et al., "Running: the risk of coronary events-prevalence and prognostic relevance of coronary atherosclerosis in marathon runners," European Heart Journal, vol. 29, no. 15, pp. 1903-1910, 2008.

[12] F. Breuckmann, S. Möhlenkamp, K. Nassenstein et al., "Myocardial late gadolinium enhancement: prevalence, pattern, and prognostic relevance in marathon runners," Radiology, vol. 251, no. 1, pp. 50-57, 2009.

[13] C. Vlachopoulos, D. Kardara, A. Anastasakis et al., "Arterial stiffness and wave reflections in marathon runners," American Journal of Hypertension, vol. 23, no. 9, pp. 974-979, 2010.

[14] L. Mont, R. Elosua, and J. Brugada, "Endurance sport practice as a risk factor for atrial fibrillation and atrial flutter," Europace, vol. 11, no. 1, pp. 11-17, 2009.

[15] M. Wilhelm, "Atrial fibrillation in endurance athletes," European Journal of Preventive Cardiology, vol. 21, no. 8, pp. 1040-1048, 2014.

[16] B. Knechtle, C. A. Rüst, T. Rosemann, and R. Lepers, "Agerelated changes in $100-\mathrm{km}$ ultra-marathon running performance," Age, vol. 34, no. 4, pp. 1033-1045, 2012.

[17] R. Lepers and T. Cattagni, "Do older athletes reach limits in their performance during marathon running?" Age, vol. 34, no. 3, pp. 773-781, 2012.

[18] R. Lepers, C. A. Rüst, P. J. Stapley, and B. Knechtle, "Relative improvements in endurance performance with age: evidence from 25 years of Hawaii Ironman racing," Age, vol. 35, no. 3, pp. 953-962, 2013.
[19] R. J. Gibbons, G. J. Balady, J. W. Beasley et al., "ACC/AHA guidelines for exercise testing: executive summary: a report of the American College of Cardiology/American Heart Association Task Force on Practice Guidelines (Committee on Exercise Testing)," Circulation, vol. 96, no. 1, pp. 345-354, 1997.

[20] M. S. Lauer, D. Levy, K. M. Anderson, and J. F. Plehn, "Is there a relationship between exercise systolic blood pressure response and left ventricular mass? The Framingham heart study," Annals of Internal Medicine, vol. 116, no. 3, pp. 203-210, 1992.

[21] S. E. Kjeldsen, R. Mundal, L. Sandvik, G. Erikssen, E. Thaulow, and J. Erikssen, "Exercise blood pressure predicts cardiovascular death and myocardial infarction," Blood Pressure Monitoring, vol. 2, no. 3-4, pp. 147-153, 1997.

[22] S. Kurl, J. A. Laukkanen, R. Rauramaa, T. A. Lakka, J. Sivenius, and J. T. Salonen, "Systolic blood pressure response to exercise stress test and risk of stroke," Stroke, vol. 32, no. 9, pp. 2036-2041, 2001.

[23] J. P. Singh, M. G. Larson, T. A. Manolio et al., "Blood pressure response during treadmill testing as a risk factor for new-onset hypertension. The Framingham heart study," Circulation, vol. 99, no. 14, pp. 1831-1836, 1999.

[24] M. F. Wilson, B. H. Sung, G. A. Pincomb, and W. R. Lovallo, "Exaggerated pressure response to exercise in men at risk for systemic hypertension," The American Journal of Cardiology, vol. 66, no. 7, pp. 731-736, 1990.

[25] P. Verdecchia, G. Schillaci, G. Reboldi, S. S. Franklin, and C. Porcellati, "Different prognostic impact of 24-hour mean blood pressure and pulse pressure on stroke and coronary artery disease in essential hypertension," Circulation, vol. 103, no. 21, pp. 2579-2584, 2001.

[26] J. Dorn, J. Naughton, D. Imamura, and M. Trevisan, "Results of a multicenter randomized clinical trial of exercise and longterm survival in myocardial infarction patients. The National Exercise and Heart Disease Project (NEHDP)," Circulation, vol. 100, no. 17, pp. 1764-1769, 1999.

[27] J. Myers, M. Prakash, V. Froelicher, D. Do, S. Partington, and J. Edwin Atwood, "Exercise capacity and mortality among men referred for exercise testing," New England Journal of Medicine, vol. 346, no. 11, pp. 793-801, 2002.

[28] G. C. Rowe, A. Safdar, and Z. Arany, "Running forward: new frontiers in endurance exercise biology," Circulation, vol. 129, no. 7, pp. 798-810, 2014.

[29] V. A. Cornelissen and N. A. Smart, "Exercise training for blood pressure: a systematic review and meta-analysis," Journal of the American Heart Association, vol. 2, no. 1, Article ID e004473, 2013.

[30] A. Schmermund, T. Voigtländer, and B. Nowak, "The risk of marathon runners-live it up, run fast, die young?" European Heart Journal, vol. 29, no. 15, pp. 1800-1802, 2008.

[31] T. Tomoto, J. Sugawara, A. Hirasawa, T. Imai, S. Maeda, and S. Ogoh, "Impact of short-term training camp on arterial stiffness in endurance runners," Journal of Physiological Sciences, vol. 65, no. 5, pp. 445-449, 2015.

[32] W. W. Nichols and D. A. McDonald, McDonald's Blood flow in Arteries: Theoretic, Experimental, and Clinical Principles, Hodder Amold, London, UK, 6th edition, 2005.

[33] R. B. Weiner, F. Wang, S. K. Isaacs et al., "Blood pressure and left ventricular hypertrophy during American-style football participation," Circulation, vol. 128, no. 5, pp. 524-531, 2013.

[34] H. M. Berge, T. E. Andersen, E. E. Solberg, and K. Steine, "High ambulatory blood pressure in male professional football 
players," British Journal of Sports Medicine, vol. 47, no. 8, pp. 521525, 2013.

[35] G. Mohácsi, S. Sonkodi, G. Abrahám et al., "The effect of chronic alcohol consumption on blood pressure," Orvosi Hetilap, vol. 132, no. 2, pp. 63-67, 1991. 


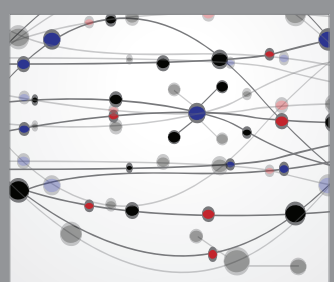

The Scientific World Journal
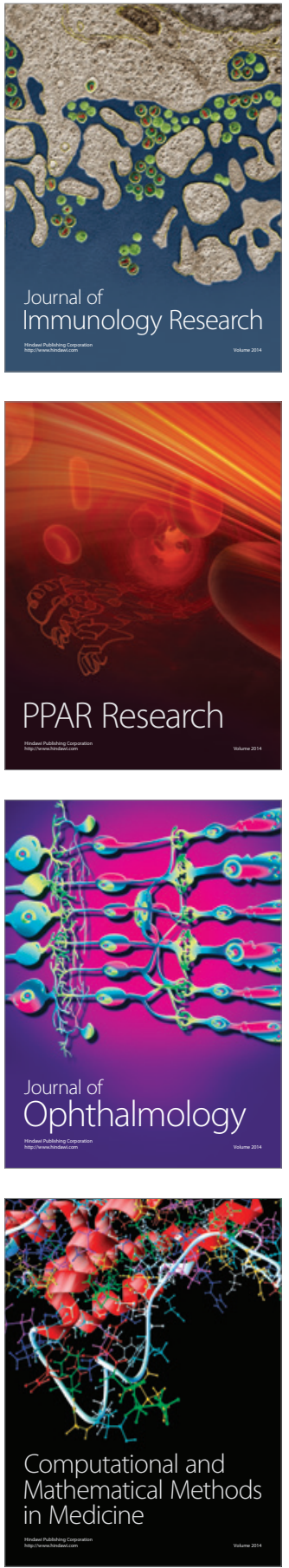

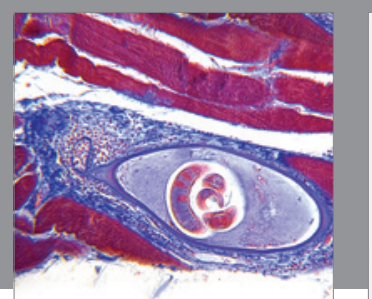

Gastroenterology Research and Practice
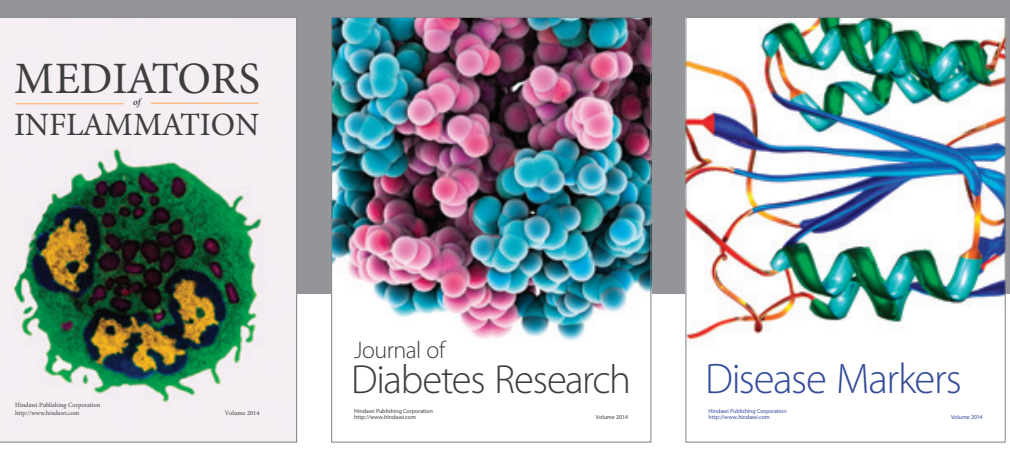

Disease Markers

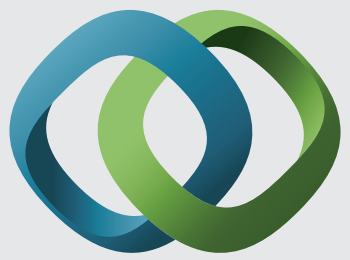

\section{Hindawi}

Submit your manuscripts at

https://www.hindawi.com
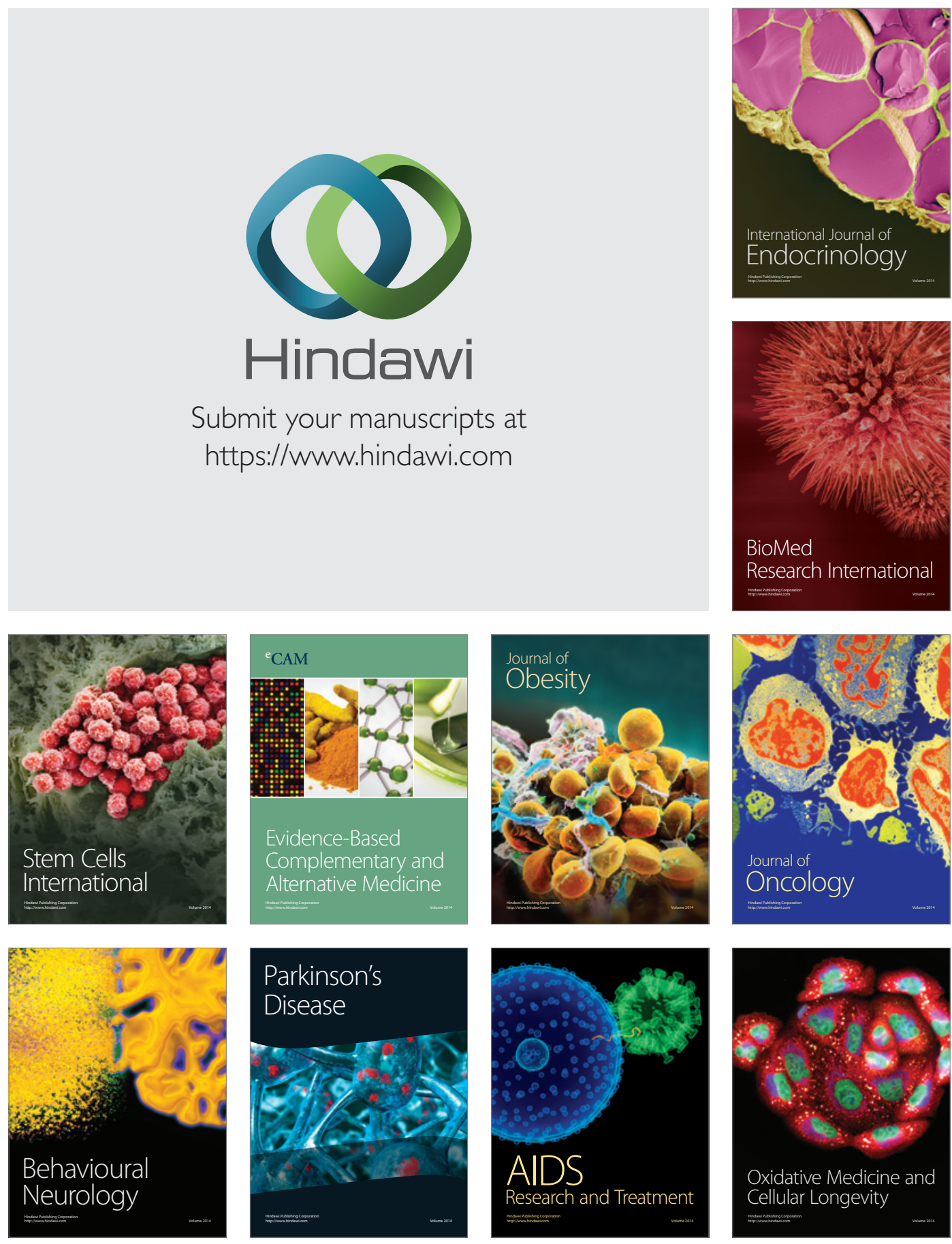